\title{
The Activity of Escherichia coli Cyclopropane Fatty Acid Synthase Depends upon the Presence of Bicarbonate
}

\author{
David F. Iwig, Akira Uchida, Jeffrey A. Stromberg, and Squire J. Booker* \\ Department of Biochemistry and Molecular Biology and Department of Chemistry. The Pennsylvania State University, \\ University Park, Pennsylvania 16802
}

\section{Experimental}

\section{Supporting Information}

Materials: Adenine, S-adenosyl-L-methionine ( $p$-toluenesulfonate salt), N-(2-hydroxyethyl)piperazineN'-(3-propane-sulfonic acid (EPPS), malic dehydrogenase (MDHase), the reduced form of $\beta$ nicotinamide adenine dinucleotide (NADH), potassium thiocyanate, and tryptophan were purchased from Sigma (St. Louis, MO). L-Methionine, potassium bicarbonate, and sodium borate were purchased from Fisher Biotech (Fair Lawn, NJ). Ethylenediaminetetraacetic acid (EDTA), formic acid, N-2hydroxyethylpiperazine-N'-2-ethanesulfonic acid (HEPES), imidazole, magnesium chloride, 2-(Nmorpholino)ethanesulfonic acid (MES) monohydrate, potassium acetate, potassium chloride, sodium nitrate, and urea were purchased from VWR International (West Chester, PA). The monosodium salt hydrate of phosphoenolpyruvic acid (PEP) and phosphoenolpyruvate carboxylase (PEPCase) were purchased from MP Biomedicals (Solon, OH). 1,2-dioleoyl-SN-glycero-3-[phospho-RAC-(1-glycerol)] (dOPG) and 1-stearoyl-2-oleoyl-SN-glycero-3-[phospho- $R A C$-(1-glycerol)] (SOPG) in chloroform were purchased from Avanti Polar Lipids, Inc. (Alabaster, AL). All solvents used for high performance liquid chromatography (HPLC) analysis were of HPLC grade or better. All other chemicals and reagents were of the highest purity available and were purchased from Sigma or Aldrich unless noted otherwise.

General Procedures: EDTA solutions that were used to terminate the bicarbonate scrubbing system were first purged of dissolved carbon dioxide by bubbling argon through the solution for more than 24 hours prior to use based on previous studies (1). Routine UV-visible spectra and single wavelength kinetic studies were recorded on a Cary (Varian, Walnut Springs, CA) 300 Bio spectrophotometer using the associated Cary WinUV software package. HPLC analysis was carried out on an 1100 system from Agilent (Foster City, CA) with variable wavelength detection, which was equipped with an autosampler to facilitate the analysis of multiple samples. HPLC data were collected and processed using ChemStation Rev. A.09.01. Ultra high purity argon gas purchased from MESSER (Morrisville, PA) was scrubbed of carbon dioxide prior to use with a carbon dioxide adsorber purchased from Alltech (Deerfield, IL). Kinetic data were analyzed using Igor Pro (Lake Oswego, OR) or GraFit (Surrey, UK) software packages.

Activity Assays of CFA Synthase: Routine activity assays of CFA synthase were performed as described previously (2). Activity assays in the presence of a bicarbonate scrubbing system (described below) were carried out in closed sample vials to keep atmospheric carbon dioxide from dissolving in the solutions subsequent to scrubbing. The assays were carried out in a final volume of $250 \mu \mathrm{L}$ and contained the following final concentrations of individual components: $70 \mathrm{mM}$ EPPS, $\mathrm{pH} 8.0,5 \mathrm{mM}$ PEP, $2 \mathrm{mM}$ $\mathrm{NADH}, 2.5 \mathrm{mM} \mathrm{MgCl} 2,0.4$ Units of PEPCase, 28 Units of MDHase, $15 \mathrm{mM}$ dOPG, 1mM tryptophan, $1.8 \mu \mathrm{M}$ CFA synthase, and $0.8 \mu \mathrm{M}$ SAHN. These components were allowed to incubate at $37^{\circ} \mathrm{C}$ for 10 minutes before EDTA was added to a final concentration of $7.5 \mathrm{mM}$. After 20 seconds, a known concentration of $\mathrm{KHCO}_{3}$ was added, followed by a known concentration of AdoMet to initiate the reaction after an additional 20 seconds. At specified times, $40 \mu \mathrm{L}$ aliquots were removed and added to 70 $\mu \mathrm{L}$ of $40 \mathrm{mM} \mathrm{H}_{2} \mathrm{SO}_{4}$ to quench the reaction. Product formation was analyzed by HPLC as previously described. Initial reaction rates as a function of substrate concentration were fitted to eq 1 by nonlinear regression, wherein $v_{0}$ is the observed initial rate at a given substrate concentration $[\mathrm{S}], V_{\max }$ is the 
maximal velocity of the reaction, and $K_{\mathrm{M}}$ is the apparent Michaelis constant for the varied substrate. Assays to determine initial rates were performed such that less than $10 \%$ of the starting concentration of AdoMet was consumed in the reaction, and the non-varied substrates were maintained at saturating concentrations.

$$
v_{0}=V_{\max }[\mathrm{S}] /\left(K_{\mathrm{M}}+[\mathrm{S}]\right)
$$

Effect of Purification Buffer and Assay Buffer on CFA Synthase Activity: Two different portions of the same cell paste were used side-by-side to isolate CFA synthase as described previously (2). One of the purifications was carried out in $50 \mathrm{mM}$ HEPES, pH 7.0, containing $300 \mathrm{mM} \mathrm{KCl}$, the typical purification buffer, while the second purification was carried out in $50 \mathrm{mM} \mathrm{KHCO}_{3}, \mathrm{pH} 7.0$, containing $300 \mathrm{mM} \mathrm{KCl}$. The final step in each of the purifications consisted of exchanging the proteins into $100 \mathrm{mM} \mathrm{HEPES,} \mathrm{pH}$ 7.0 (for the isolation carried out in HEPES buffer) or $100 \mathrm{mM} \mathrm{KHCO}_{3}, \mathrm{pH} 7.0$ (for the isolation carried out in $\mathrm{KHCO}_{3}$ buffer) using Sephadex G-25 resin. After concentrating to $\sim 300 \mu \mathrm{M}$, the proteins were mixed with an equal volume of $50 \%$ glycerol and stored at $78^{\circ} \mathrm{C}$ until needed. Activity assays of both of the purified enzymes were carried out as previously described (2), and contained $70 \mathrm{mM}$ HEPES, pH 7.0, or $70 \mathrm{mM} \mathrm{KHCO}_{3}$, pH 7.0, $0.8 \mu \mathrm{M}$ CFA synthase, $0.5 \mu \mathrm{M}$ AdoHcys nucleosidase, $1 \mathrm{mM}$ L-tryptophan (internal standard, IS), $15 \mathrm{mM} \mathrm{dOPG}$, and 10-400 $\mu \mathrm{M}$ AdoMet, synthesized as described earlier (2).

Inhibition of CFA synthase by Analogs of Bicarbonate: Activity assays in the presence of analogs of bicarbonate were carried out in a final volume of $250 \mu \mathrm{L}$ and contained the following: $70 \mathrm{mM} \mathrm{EPPS}, \mathrm{pH}$ 8.0, $5 \mathrm{mM}$ PEP, $2 \mathrm{mM}$ NADH, $2.5 \mathrm{mM} \mathrm{MgCl}$, 0.40 U PEPCase, $28 \mathrm{U}$ MDHase, $15 \mathrm{mM}$ dOPG, $1 \mathrm{mM}$ tryptophan, $1.8 \mu \mathrm{M}$ CFA synthase, $0.8 \mu \mathrm{M}$ AdoHcys nucleosidase, and 2-12 $\mathrm{mM}$ of the inhibitor. The reaction mixture was allowed to incubate at $37^{\circ} \mathrm{C}$ for $10 \mathrm{~min}$ before adding EDTA to a final concentration of $7.5 \mathrm{mM}$. After incubating for an additional $30 \mathrm{~s}, \mathrm{KHCO}_{3}$ was added to a final concentration of $200 \mu \mathrm{M}$. After incubating once more for $30 \mathrm{~s}$, CFA synthase turnover was then initiated by adding AdoMet to a final concentration of $500 \mu \mathrm{M}$. The bicarbonate analogs examined were acetate, borate, formate, nitrate, trithiocarbonate, and urea, each at 2, 4, 8, and $12 \mathrm{mM}$. All analog solutions were titrated to neutral $\mathrm{pH}$ with $\mathrm{KOH}$ or $\mathrm{HCl}$ prior to use. An inhibition constant $\left(K_{\mathrm{I}}\right)$ was determined for borate as described above by varying the concentration of bicarbonate $(28$ to $400 \mu \mathrm{M})$ at fixed concentrations $(0.75,1.5$, and 3.0 $\mathrm{mM}$ ) of borate. The data were globally fitted to eq 2 using GraFit to determine the type of inhibition and the $K_{\mathrm{I}}$.

$$
v=\frac{V_{\max } \cdot[S]}{K_{m}\left(1+\frac{[I]}{K_{i}}\right)+[S]}
$$

(1) Hall, N. P., Cornelius, M. J., Keys, A. J. Anal. Biochem. 1983, 132, 152-157.

(2) Iwig, D. F., Grippe, A. T., McIntyre, T. A., Booker, S. J. Biochemistry 2004, 43, 13510-13524. 